Bull. Fac.Agric., Cairo Univ. 64:59-66 (2013)

\title{
ANALYSIS OF JOJOBA OIL EXTRACTED FROM in vitro CALLUS AND SEEDS BY GC/MS.
}

(Received:30.1.2013)

\author{
By \\ E.M. Badawy, O.M.El-Shehy*, A.M.Habeb and D. A. Ahmed \\ Department of Ornamental Horticulture, * Department of Botany "Phesulogy Section" \\ Faculty of Agriculture, Cairo University, Giza
}

\begin{abstract}
The jojoba oil extracted from various types of callus for Simmondsia chinensis and the jojoba seeds; had been analyzed using the combined separation and analytical technique by Gas Chromatography-Mass Spectrometry (GC-MS). Oil of grinded seeds, yellowish compact callus (S1), greenish white semicompact callus (S2) and green friable callus (S3); cultured on MS media containing different concentrations of growth regulators, and Knop's medium supplemented with TDZ (2mg/l) were used for analysis. It was found that the major fatty acids for $\mathrm{S} 1$ sample were gadoleic acid $\left(\mathrm{C}_{20: 1} ; 27.01 \%\right)$, oleic acid $\left(\mathrm{C}_{18: 1} ; 15.46 \%\right)$ and nervonic acid $\left(\mathrm{C}_{24: 1} ; 10.15 \%\right)$, while the most excited for $\mathrm{S} 2$ oil were $\mathrm{C}_{16}$ dicarboxylic acid (11.27\%) and arachidic acid $\left(\mathrm{C}_{20} ; 10.6 \%\right)$. In case of green friable callus, nervonic acid $\left(\mathrm{C}_{24: 1}\right)$ was the most found fatty acid in its oil extract $(50.65 \%)$. The oil extracted from seeds (control), contained gadoleic acid $\left(\mathrm{C}_{20: 1} ; 42.61 \%\right)$, oleic acid $\left(\mathrm{C}_{18: 1} ; 15.9 \%\right)$ and erucic acid $\left(\mathrm{C}_{22: 1} ; 9.73 \%\right)$. The composition of medium was effective indetermining different fatty acids which varied in their quality and quantity.
\end{abstract}

Key words: Jojoba oil, GC/MS, Fatty acids

\section{INTRODUCTION}

Jojoba (Simmondsia chinensis) plant is native to Sonoran Desert of Northern Mexico and South Western USA, also known as goat nut, deer nut, pignut, wild hazel, quinine nut, coffeeberry, and gray box bush. It belongs to the Simmondsiaceae family. It is a dioecious plant, with hermaphrodite flowers being extremely rare. It is highly saline-tolerant woody shrub of arid, semiarid or marginal lands (Hogan, 1979).

Jojoba as a commercial crop is cultivated today for its wax. The oil represents $50 \%$ of the jojoba seed by weight, is colorless, odorless and does not break down quickly at high temperatures with unique physical and chemical properties. It was used mostly in the cosmetics and lubricants industries because of its superior lubricating ability and uniform viscosity over a wide range of temperatures (Low and Hackett 1981and Wang and Janick 1986). This increased interest in the agricultural production of jojoba but it is a crop that requires further research and development to improve quality and consistency of yields (Lee, 1988).

Jojoba oil is a mixture of wax esters, with 36 to 46 carbon atoms in length. Each molecule consists of a fatty acid and a fatty alcohol joined by an ester bond. The approximate percentages of fatty acids in jojoba oil are as follows: Eicosenoic $(66-71 \%)$, Docosenoic (14-20\%) and Oleic (10$13 \%)$.

Gayland et al., (1977) described and compared two analytical procedures for determining composition of jojoba liquid wax esters. First, the more tedious, involves separation of wax ester homologs by high pressure liquid chromatography (HPLC), followed by determination of the acid and alcohol moieties from each homolog. The second allows rapid determination of wax ester composition by gas chromatographic (GC) separation of hydrogenated jojoba wax esters according to chain length, followed immediately by ancillary mass spectrometric identification of the acid and alcohol moieties. Double bonds in the alkyl chains in jojoba liquid waxes were almost exclusively (98\%) $w-9$, when examined by gas chromatography/ mass spectrometry (GC/MS) and ozonolysis/GC/MS. Zouari et al. (2012) reported that the chemical characterization of Allium roseum var. odoratissimum, and identified new bioactive natural compounds in its flower essential oil. These compounds were extracted by hydrodistillation and were analyzed by GC and GC/MS, 
using an apolar column. Kayani et al. (1990) reported that, HPLC and GC-MS were used to analyze jojoba wax ester and fatty acid composition. Fatty alcohols were determined by a different method that assumes a molar material balance.

The objective of this study was to use GCMS analysis of fatty acids to monitor changes in the composition of jojoba oil extraction from callus grown in media supplemented with different compounds (salts and growth regulators) and were compared with each other in comparison with the control (oil extract from grinded seeds).

\section{MATERIALS AND METHODS}

The jojoba seeds were obtained from the Natural Oils Unit, National Research CenterDokki, Egypt. The GC-MS analysis of samples was carried out at the Plant Pathology Research Institute, Agricultural Research Center, Giza, Egypt.

\subsection{Samples type uses}

-Seeds (control)

$-\mathrm{S} 1$ = callus (yellowish compact callus) grown on MS medium (Murashige and Skoog, 1962) supplemented with $1.5 \mathrm{mlll} 2,4-\mathrm{D}+2 \mathrm{ml} / \mathrm{l}$ NAA

$-\mathrm{S} 2=$ callus (greenish white semi-compact callus) grown on MS medium supplemented with $5.5 \mathrm{ml} / \mathrm{l} \mathrm{BA}$ (benzylaminopurine) $+2.5 \mathrm{ml} / \mathrm{l} \mathrm{NAA}$ (naphthaleneacetic acid)

$-\mathrm{S} 3$ = callus (green friable callus) grown on Knops' medium supplemented with $2 \mathrm{ml} / 1 \mathrm{TDZ}$ (thidiazuron)

\subsection{Extraction of jojoba oil}

All samples (callus and grinded seeds) were collected and immediately stored at $-20^{\circ} \mathrm{C}$ before subjecting to fatty acid extraction. The oil content of the samples was determined by complete extraction using Soxhlet extractor. Solvents used for oil extraction were commercial hexane: methanol $1: 1$ at $60^{\circ} \mathrm{C}$ for $12 \mathrm{~h}$.

\subsection{Methylation of fatty acids}

Thirty milligrams of oil were placed with $0.5 \mathrm{ml}$ reagent $(45 \mathrm{~g} \mathrm{NaOH}, 150 \mathrm{ml}$ methanol, 150 $\mathrm{ml} \mathrm{H}_{2} \mathrm{O}$ ) in a capped heat-resistant glass tube. Saponification of fatty acid methyl ester was conducted by heating the tube for $30 \mathrm{~min}$ then put in an oven at $100^{\circ} \mathrm{C}$ for $3 \mathrm{~h}$. The tubes were then cooled down quickly to room temperature in a water bath. Finally, the methyl esters of fatty acids were subjected to GC-MS analysis.

\subsection{Method of analysis}

\subsubsection{GC-MS analysis Instrument operating conditions}

GC-MS analyses were performed on an Agilent 6890 series II gas chromatograph ,an Agilent 5973 mass spectrometer with electron ionization, mode (EI) generated at $70 \mathrm{eV}$ (ion source at $230{ }^{\circ} \mathrm{C}$ and transfer line at $280{ }^{\circ} \mathrm{C}$ ). The GC was performed using a HP5-MS capillary column $(30 \mathrm{~m} \times 0.25 \mathrm{~mm}$, film thickness of 0.25 $\mu \mathrm{m})$. Operating conditions were as follows: carrier gas, helium with a flow rate of $\left(1 \mathrm{ml} \mathrm{min}{ }^{-1}\right)$. The oven temperature was programmed from $80{ }^{\circ} \mathrm{C}$ to $280{ }^{\circ} \mathrm{C}\left(\right.$ at $\left.8{ }^{\circ} \mathrm{C} \mathrm{min}^{-1}\right)$, and maintained at $260{ }^{\circ} \mathrm{C}$ for $5 \mathrm{~min}$.

All compounds were identified by comparison of both the mass spectra (Wiley and Nist library). The ratio of the compounds specific peaks were indicated by giving an Area\% and retention time (Rt).

3.1. Jojoba oil

The oil yield from jojoba plant seeds and their respective callus cultures grown on different media composition were compared. Jojoba oil was obtained from seeds (cotyledons) and from all samples (S1, S2 and S3) of callus cultures. Lee and Thomas (1985) obtained cotyledonary structures arising from asexual embryos in jojoba. These cotyledonary structures contained wax bodies and liquid wax identical to that of seeds. Under all experimental conditions, jojoba tissues contained high amount of lipids. Gaber (1993) also obtained in vitro jojoba liquid wax from somatic embryos. GC/MS method could be applied only to fully saturated wax esters (Aasen et al. 1971).

Data in Tables (1, 2, 3, and 4) and Figures (1, 2, 3 and 4), showed that $\mathrm{C}_{17}$ (margaric acid) and $\mathrm{C}_{18}$ (stearic acid) fatty acids were the main saturated fatty acids in all oil extracted in this investigation. It was found that the proportion of both fatty acids differed between the samples. However, the highest percent of $\mathrm{C}_{17}$ was obtained in $\mathrm{S} 3(1.33 \%)$, followed by $0.58 \%$ obtained from $\mathrm{S} 2$, while the lowest proportion was obtained from $\mathrm{S} 1$ and the control (0.15 and $0.34 \%$, respectively). Likewise, the $\mathrm{C}_{18}$ resides in all samples in descending order, S2, control, S3 and S1 giving $2.35,2.09,0.59$ and $0.17 \%$, respectively.

Regarding to the control (oil extracted from seeds) as compared to that extracted from callus (S1, S2 and S3) under investigation, it was found that $\mathrm{C}_{12}$ ratio for control was $2.78 \%$, increased in S3 to $9.48 \%$, and decreased in S1 to $1.18 \%$, while it was absent in $\mathrm{S} 2$.

The $\mathrm{C}_{14}$ fatty acid was one of the main fatty 
Table (1): Fatty acid constituents quantified in jojoba oil extracted from grinded seeds (control) analysis by GC-MS.

\begin{tabular}{ccllll}
\hline $\begin{array}{c}\text { Peak } \\
\text { No. }\end{array}$ & $\begin{array}{c}\text { Rt } \\
\text { (min) }\end{array}$ & $\begin{array}{l}\text { Carbon } \\
\text { atoms }\end{array}$ & Systematic name & Trivial name & Area \% \\
\hline $\mathbf{1}$ & 4.390 & $\mathrm{C}_{12}$ & Dodecanoic acid & Lauric acid & \\
$\mathbf{2}$ & 5.683 & $\mathrm{C}_{13}$ & Tridecanoic acid & Tridecylic acid & 2.78 \\
$\mathbf{3}$ & 6.090 & - & u.n & u.n & 1.24 \\
$\mathbf{4}$ & 7.080 & $\mathrm{C}_{14}$ & Tetradecanoic acid & Myristic acid & 1.65 \\
$\mathbf{5}$ & 9.929 & $\mathrm{C}_{16}$ & Hexadecanoic acid & Palmitic acid & 0.96 \\
$\mathbf{6}$ & 11.308 & $\mathrm{C}_{17}$ & Heptadecanoic acid & Margaric acid & 0.34 \\
$\mathbf{7}$ & 11.463 & - & u.n & u.n & 0.78 \\
$\mathbf{8}$ & 12.636 & $\mathrm{C}_{18}$ & Octadecanoic acid & Stearic acid & 2.09 \\
$\mathbf{9}$ & 17.179 & $\mathrm{C}_{18: 1}$ & Octadecenoic acid & Oleic acid & 15.90 \\
$\mathbf{1 0}$ & 19.937 & $\mathrm{C}_{20}$ & Eicosanoic acid & Arachidic acid & 7.29 \\
$\mathbf{1 1}$ & 20.560 & $\mathrm{C}_{20: 1}$ & Eicosenoic acid & Gadoleic acid & 42.61 \\
$\mathbf{1 2}$ & 21.556 & - & u.n & u.n & 1.94 \\
$\mathbf{1 3}$ & 23.496 & $\mathrm{C}_{20: 2}$ & Eicosadienoic acid & - & 4.97 \\
$\mathbf{1 4}$ & 24.097 & $\mathrm{C}_{22: 1}$ & Docosenoic acid & Erucic acid & 9.73 \\
$\mathbf{1 5}$ & 24.932 & - & u.n & u.n & 2.38 \\
$\mathbf{1 6}$ & 27.610 & - & u.n & u.n & 1.78 \\
$\mathbf{1 7}$ & 31.529 & - & u.n & u.n & 2.32 \\
\hline
\end{tabular}

$R t=$ retention time, Non identified peaks $=10.85 \%$, Identified peaks $=89.15 \%$, u.n $=$ unknown.

Table (2): Fatty acid constituents quantified in jojoba oil extracted from in vitro yellowish compact callus culture (S1) analysis by GC-MS.

\begin{tabular}{cclllc}
\hline $\begin{array}{c}\text { Peak } \\
\text { No. }\end{array}$ & $\begin{array}{c}\text { Rt } \\
(\mathbf{m i n})\end{array}$ & $\begin{array}{l}\text { Carbon } \\
\text { atoms }\end{array}$ & Systematic name & Trivial name & \\
\hline $\mathbf{1}$ & 4.396 & $\mathrm{C}_{12}$ & Dodecanoic acid & Lauric acid & \\
$\mathbf{2}$ & 5.683 & - & u.n & u.n & 1.18 \\
$\mathbf{3}$ & 6.976 & $\mathrm{C}_{14: 1}$ & Tetradecenoic acid & Myristoleic acid & 1.00 \\
$\mathbf{4}$ & 7.079 & - & u.n & u.n & 0.43 \\
$\mathbf{5}$ & 8.922 & - & u.n & u.n & 1.25 \\
$\mathbf{6}$ & 9.837 & $\mathrm{C}_{16: 1}$ & Hexadecenoic acid & Palmitoleic acid & 0.43 \\
$\mathbf{7}$ & 10.501 & - & u.n & u.n & 9.90 \\
$\mathbf{8}$ & 11.308 & $\mathrm{C}_{17}$ & Heptadecanoic acid & Margaric acid & 0.48 \\
$\mathbf{9}$ & 11.371 & $\mathrm{C}_{18}$ & Octadecanoic acid & Stearic acid & 0.15 \\
$\mathbf{1 0}$ & 11.777 & - & u.n & u.n & 0.17 \\
$\mathbf{1 1}$ & 12.555 & $\mathrm{C}_{18: 1}$ & Octadecenoic acid & Oleic acid & 1.46 \\
$\mathbf{1 2}$ & 14.461 & - & u.n & u.n & 15.46 \\
$\mathbf{1 3}$ & 15.388 & $\mathrm{C}_{20: 1}$ & Eicosenoic acid & Gadoleic acid & 3.18 \\
$\mathbf{1 4}$ & 17.196 & $\mathrm{C}_{18: 1}$ trans & Octadecenoic acid & Oleic acid "trans" & 27.01 \\
$\mathbf{1 5}$ & 17.585 & - & u.n & u.n & 0.79 \\
$\mathbf{1 6}$ & 22.088 & $\mathrm{C}_{22: 1}$ & Docosenoic acid & Erucic acid & 0.93 \\
$\mathbf{1 7}$ & 14.932 & - & u.n & u.n & 6.65 \\
$\mathbf{1 8}$ & 25.596 & $\mathrm{C}_{23: 1}$ & Tricosenoic acid & Tricosene & 4.41 \\
$\mathbf{1 9}$ & 28.417 & $\mathrm{C}_{24: 1}$ & Tetracosenoic acid & Nervonic acid & 4.49 \\
$\mathbf{2 0}$ & 29.160 & - & u.n & u.n & 10.15 \\
$\mathbf{2 1}$ & 29.893 & - & u.n & u.n & 5.48 \\
$\mathbf{2 2}$ & 31.026 & - & u.n & u.n & 3.29 \\
& & & & 1.71 \\
\end{tabular}

$R t=$ retention time, Non identified peaks $=23.62 \%$, Identified peaks= $\mathbf{7 6 . 3 8 \% , ~ u . n = ~ u n k n o w n . ~}$ 
Table (3): Fatty acid constituents quantified in jojoba oil extracted from in vitro greenish white semicompact callus culture (S2) analysis by GC-MS.

\begin{tabular}{|c|c|c|c|c|c|}
\hline \multirow{2}{*}{$\begin{array}{l}\text { Peak } \\
\text { No. }\end{array}$} & \multirow{2}{*}{$\underset{(\mathbf{m i n})}{\mathbf{R t}}$} & \multicolumn{3}{|c|}{ Components } & \multirow[t]{2}{*}{ Area \% } \\
\hline & & $\begin{array}{l}\text { Carbon } \\
\text { atoms }\end{array}$ & Systematic name & Trivial name & \\
\hline 1 & 7.886 & - & u.n & u.n & 0.07 \\
\hline 2 & 9.625 & - & u.n & u.n & 1.54 \\
\hline 3 & 14.357 & $\mathrm{C}_{16}$ & Hexadecanoic acid & Palmitic acid & 0.50 \\
\hline 4 & 15.187 & - & u.n & u.n & 0.17 \\
\hline 5 & 15.768 & $\mathrm{C}_{17}$ & Heptadecanoic acid & Margaric acid & 0.58 \\
\hline 6 & 15.924 & $\mathrm{C}_{16}$ & $\begin{array}{l}\text { Octanoic acid, 2- } \\
\text { ethylhexyl ester }\end{array}$ & C16 ester & 3.09 \\
\hline 7 & 16.603 & - & u.n & u.n & 0.99 \\
\hline 8 & 17.112 & $\mathrm{C}_{18}$ & Octadecanoic acid & Stearic acid & 2.35 \\
\hline 9 & 17.361 & $\mathrm{C}_{18: 1}$ & Octadecenoic acid & Oleic acid & 0.46 \\
\hline 10 & 17.646 & - & u.n & u.n & 1.43 \\
\hline 11 & 18.897 & $\mathrm{C}_{18: 2}$ & $\begin{array}{l}9,12 \text {-octadecadienoic } \\
\text { acid }\end{array}$ & Linoleic acid & 3.03 \\
\hline 12 & 19.410 & - & u.n & u.n & 4.61 \\
\hline 13 & 19.608 & - & u.n & u.n & 4.43 \\
\hline 14 & 20.780 & $\mathrm{C}_{19}$ & Nonadecane & Nonadecanoic & 1.15 \\
\hline 15 & 21.221 & $\mathrm{C}_{20}$ & Eicosanoic acid & acid & 10.60 \\
\hline 16 & 21.574 & - & u.n & Arachidic acid & 1.79 \\
\hline 17 & 22.124 & - & u.n & u.n & 2.76 \\
\hline 18 & 23.048 & - & u.n & u.n & 4.58 \\
\hline 19 & 23.515 & - & u.n & u.n & 3.14 \\
\hline 20 & 24.781 & - & u.n & u.n & 8.42 \\
\hline 21 & 25.087 & - & u.n & u.n & 7.59 \\
\hline 22 & 25.704 & $\mathrm{C}_{16}$ & $\begin{array}{l}1,2- \\
\text { Benzenedicarboxylic } \\
\text { acid, mono( } 2- \\
\text { ethylhexyl) ester }\end{array}$ & $\begin{array}{l}\text { u.n } \\
\text { C16 dicarboxylic } \\
\text { acid }\end{array}$ & 11.27 \\
\hline 23 & 26.161 & - & u.n & & 3.01 \\
\hline 24 & 26.565 & - & u.n & u.n & 8.04 \\
\hline 25 & 27.557 & - & u.n & u.n & 7.73 \\
\hline 26 & 28.963 & - & u.n & u.n & 3.96 \\
\hline 27 & 29.590 & - & u.n & u.n & 1.63 \\
\hline 28 & 29.917 & - & u.n & u.n & 1.08 \\
\hline
\end{tabular}

$\mathrm{Rt}=$ retention time, Non identified peaks $=67.97 \%$, Identified peaks $=33.03 \%$, u.n $=$ unknown .

acids found in jojoba oil, having $0.96 \%$ ratio for control, while in S3 it was $2.01 \%$ and was absent in $\mathrm{S} 2$. $\mathrm{S} 1$ contained $\mathrm{C}_{14: 1}$ (myristoleic acid), at the ratio of $0.43 \%$.

The results and chromatograms obtained from GC-MS analysis revealed that palmitic acid $\left(\mathrm{C}_{16}\right)$ was the dominant saturated fatty acid in all investigated oil standard taken from seeds and callus. It was $1.24 \%$ for control as compared with S3 (3.41\%), while it was $0.5 \%$ for S2 and, for it had two different types of $\mathrm{C}_{16}$, i.e. $\mathrm{C}_{16}$ ester (3.09\%) and $\mathrm{C}_{16}$ dicarboxylic acid at high ratio $(11.27 \%)$, while the palmitoleic acid $\left(\mathrm{C}_{16: 1}\right)$ was found in S1 at the ratio of $9.9 \%$.
The results showed also that the gadoleic acid (eicosenoic acid; C20:1) represented the highest percentage of total fatty acids $(42.61 \%)$, followed by oleic acid $\left(\mathrm{C}_{18: 1}\right)$ of $15.9 \%$ in oil of control, as compared with S1 $(27.01$ and $15.46 \%$ respectively), while $\mathrm{C}_{20: 1}$ was not found in $\mathrm{S} 2$ but $\mathrm{C}_{18: 1}$ was found $(0.46 \%)$. In $\mathrm{S} 3$, did not contain any of them.

As for eicosenoic acid, this study agreed with that by Thomas, (1971) where the eicosenoic acid was the major constituent that contributed to the non random wax formation, where as the percentage of the major component, eicosenoic acid in seed samples, remained unchanged at 35\% of the total jojoba oil. 


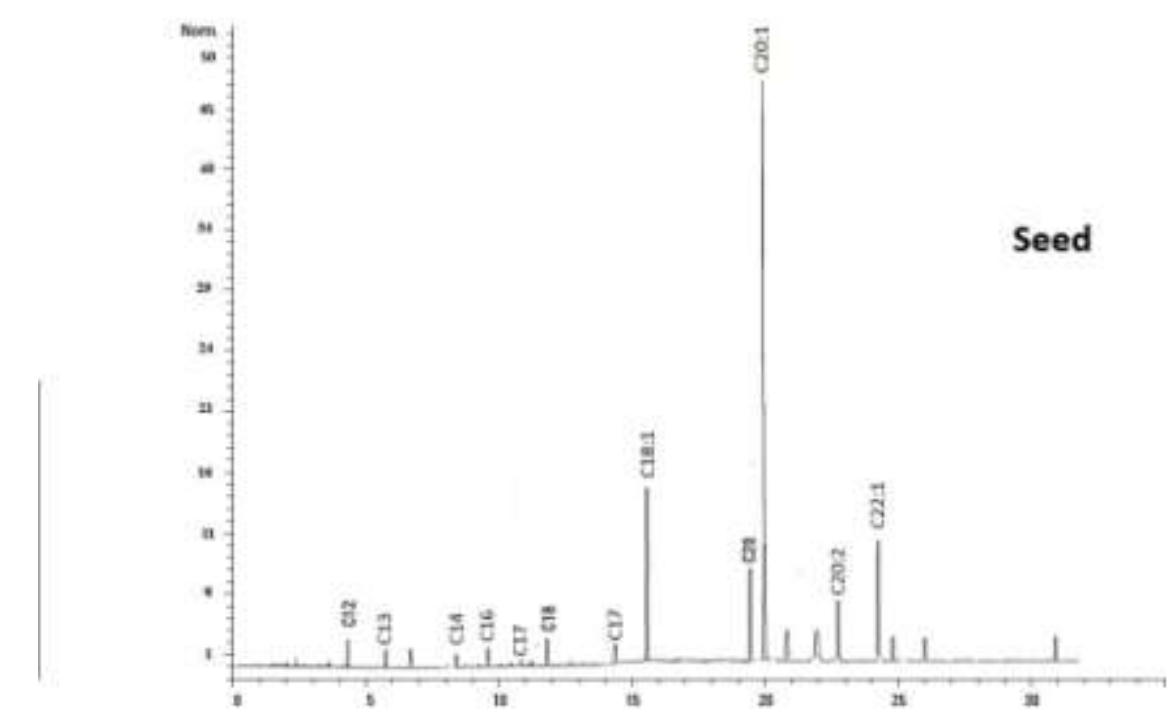

Fig (1): GC-MS chromatogram of fatty acid constituent quantified in jojoba oil extracted from seeds (control).

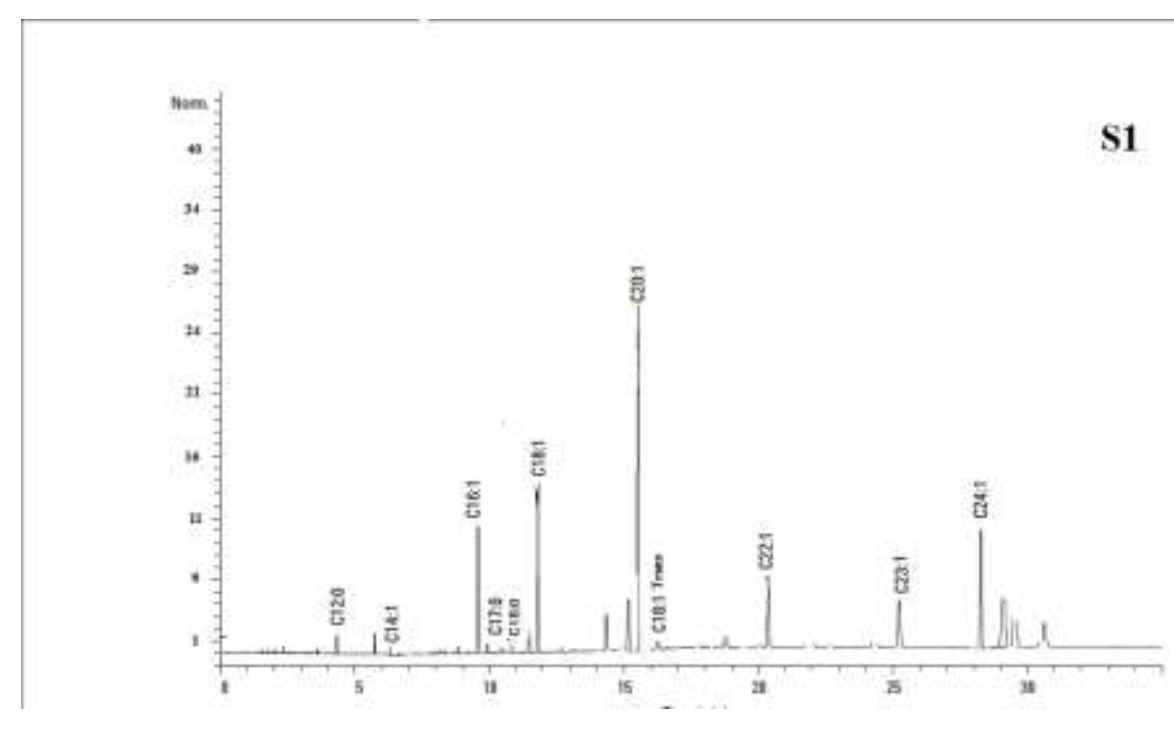

\section{Fig(2): GC-MS chromatogram of fatty acid constituent quantified in jojoba oil extracted from S1 sample}

Concerning to erucic acid $\left(\mathrm{C}_{22: 1}\right)$, the results showed that both $\mathrm{S} 2$ and $\mathrm{S} 3$ did not have this kind, but the control and $\mathrm{S} 1$ contained a high proportion of this fatty acid (9.73 and $6.65 \%$, respectively).

The obtained data in Tables $1,2,3$, and 4 and Figures (1, 2, 3 and 4) gave an explaination where $\mathrm{C}_{13}$ and $\mathrm{C}_{20: 2}$ were absent in all treatments of callus cultures, they were existed in the control.

However, the total components identified for control, S1 and S3 (89.15, 76.38 and $74.72 \%$, respectively) were higher than that of $\mathrm{S} 2$ $(33.03 \%)$.

In this study, jojoba oil was obtained from seeds (cotyledons) and callus cultures on various media types and hormones (treatments). Accordingly, the oil extracted from callus contained types of fatty acids varied in quantity and quality from the oil extracted from seeds. This variation may be due to the effect of components of the media and growth regulators used. There are several reports on the substantial influence of plant growth regulators such as auxin (2, 4-D) and cytokinin (BA) on plant lipid composition and lipid metabolism in terms of fatty acids induction and alteration of their composition (Wennuan et al., 1995; Banibrata and Gadgil 1984; Marta, 1993 and Matsuda et al.,2001). In another study relating the structure-activity relationship (Roja et al., 1987), biosynthesis of secondary products was best reported in callus and suspension cultures and altered metabolism had been also observed during organ differentiation. 


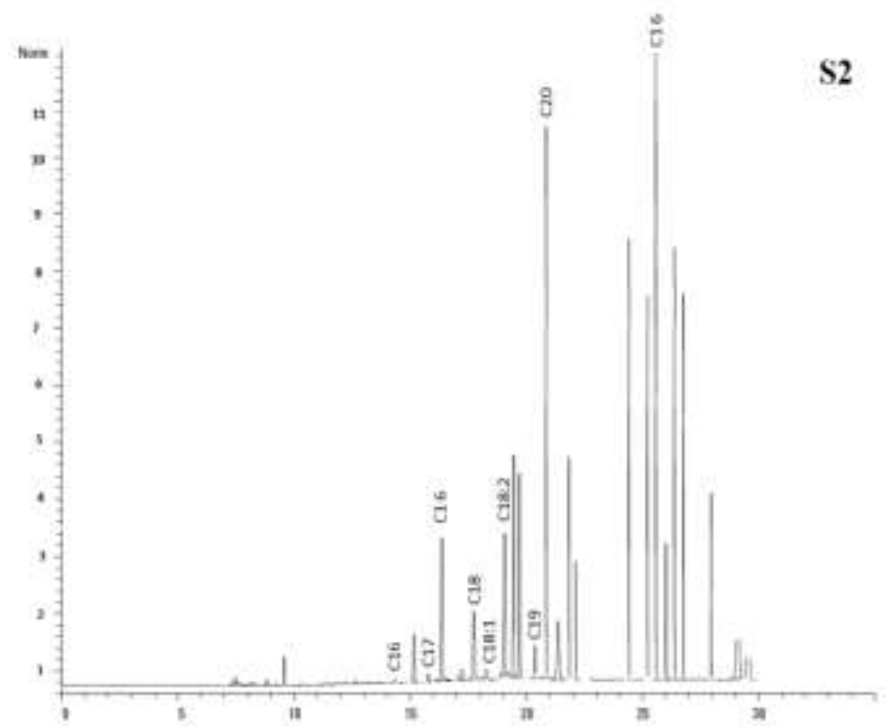

Fig (3): GC-MS chromatogram of fatty acid constituents quantified in jojoba oil extracted from $\mathrm{S} 2$ sample.

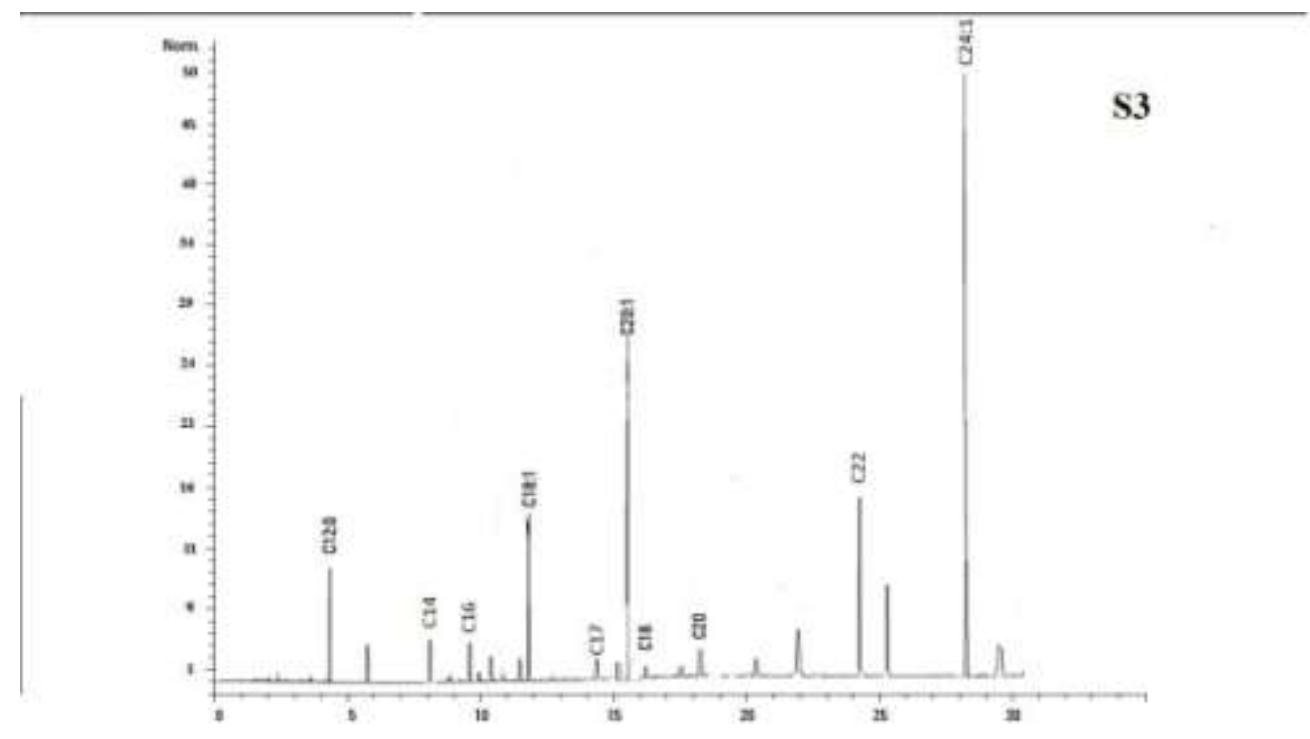

Fig(4): GC-MS chromatogram of fatty acid constituents quantified in jojoba oil extracted from S3 sample.

Consequently, yield of secondary products may either decrease or even increase further. Reported oil yields from various cultures also vary between different samples and it is not known whether this reflects environmental or genetic differences between cultures (Allan et al., 1998).
The recap, in view of increasing commercial demand of jojoba oil, the results from the present investigation foresee further refinement and standardization of plant cell and tissue culture protocols to provide an alternative means for oil recovery. 
Table (4): Fatty acids constituents quantified in jojoba oil extracted from in vitro green friable callus culture (S3) analysis by GC-MS.

\begin{tabular}{|c|c|c|c|c|c|}
\hline \multirow{2}{*}{$\begin{array}{c}\text { Peak } \\
\text { No. }\end{array}$} & \multirow{2}{*}{$\begin{array}{c}\mathbf{R t} \\
(\mathbf{m i n})\end{array}$} & \multicolumn{3}{|c|}{ Components } & \multirow[t]{2}{*}{ Area \% } \\
\hline & & $\begin{array}{r}\text { Carbon } \\
\text { atoms }\end{array}$ & Systematic name & Trivial name & \\
\hline 1 & 4.379 & $\mathrm{C}_{12}$ & Dodecanoic acid & Lauric acid & 9.48 \\
\hline 2 & 6.067 & - & u.n & u.n & 2.55 \\
\hline 3 & 7.074 & $\mathrm{C}_{14}$ & Tetradecanoic acid & Myristic acid & 2.01 \\
\hline 4 & 8.510 & - & u.n & u.n & 0.81 \\
\hline 5 & 9.929 & $\mathrm{C}_{16}$ & Hexadecanoic acid & Palmitic acid & 3.41 \\
\hline 6 & 11.462 & - & u.n & u.n & 2.31 \\
\hline 7 & 14.592 & $\mathrm{C}_{17}$ & Heptadecanoic acid & Margaric acid & 1.33 \\
\hline 8 & 15.491 & - & u.n & u.n & 1.61 \\
\hline 9 & 17.654 & $\mathrm{C}_{18}$ & Octadecanoic acid & Stearic acid & 0.59 \\
\hline 10 & 18.729 & - & u.n & u.n & 0.49 \\
\hline 11 & 19.988 & $\mathrm{C}_{20}$ & Eicosanoic acid & Arachidic acid & 1.19 \\
\hline 12 & 20.349 & - & u.n & u.n & 2.01 \\
\hline 13 & 23.227 & - & u.n & u.n & 1.07 \\
\hline 14 & 24.720 & - & u.n & u.n & 4.50 \\
\hline 15 & 24.938 & $\mathrm{C}_{22}$ & Docosanoic acid & Behnic acid & 14.02 \\
\hline 16 & 28.394 & $\mathrm{C}_{24: 1}$ & Tetracosenoic acid & Nervonic acid & 50.65 \\
\hline 17 & 29.904 & - & u.n & u.n & 1.97 \\
\hline
\end{tabular}

\section{REFERENCES}

Aasen A. J., Hofstetter H.H. Iyengar B.T. and Holman R.T. (1971). Identification and analysis of wax esters by mass spectrometry. Lipids 6 : 502-507.

Allan E.J., Stuchbury T. and Mordue A. J. (1998). In vitro culture, micropropagation and the production of azadirachtin and other secondary metabolites. Biotechnol. Agric. Forest., 43:115118.

Banibrata P. and Gadgil V.N. (1984). Fatty acids in callus cultures: influence of growth factors on fatty acid composition of total lipids in callus cells. Phytochemistry 23(1):51-53.

Gabr M. F. (1993). In vitro production of jojoba (Simmondsia chinensis) liquid wax from somatic embryos proliferation via vegetative tissues. Egyptian Journal Hort., 20: 135-144.

Gayland F. S. , Ronald D. P. and Thomas M. (1977). Jojoba oil analysis by high pressure liquid chromatography and gas chromatography/mass spectrometry1. J. of the Am. Oil Chem. Soc. 54(5): 187-189.

Hogan L. (1979). Jojoba: A crop of arid regions.

In: "New Agricultural Crops" (Ed. Richie,G.). pp: 177-205. West view Press, Boulder.

Kayani S. A., Naqvi H. H., Ting I. P. and Kumamoto J. (1990 ). Effect of salinity on fatty acid and fatty alcohol composition during the germination of jojoba (Simmondsia chinensis) seeds. J. of Agric. Food Chem. 38: (5) 1269-1271.

Lee, C. W. (1988). Application of plant biotechnology for clonal propagation and yield enhancement in jojoba. Cited after: Baldwin, A. R. ed. Proceedings of the Seventh International Conference on Jojoba and Its Uses. Illinois, United States, American Oil Chemists' Society. Pp. 102-211.

Lee, C.W. and Thomas J.C. (1985). Jojoba embryo culture and oil production. Hort. Sci., 20: 762764.

Low C. B. and Hackett W. P. (1981). Vegetative propagation of jojoba. California agriculture 35(3/4): 12-13.

Marta G. (1993). A re-evaluation of the effect of auxin on phospholipids in pea stem segments. Plant Sci 92:19-25.

Matsuda K., Buckingham S. D., Kleier D., Rauh J. J., Grauso M. and Sattelle D. B. (2001). Insecticides acting on insect nicotinic acetylcholine receptors. Trends Pharm. Sci. 22: 573.580

Murashige T. and Skoog F. (1962). A revised medium for rapid growth and bio-assay with tobacco tissue cultures. Physiologiaplantarum 15: 473-497. 
Roja P.C. Sipahimalani A.T., Heble M.R. and Chadha M.S. (1987). Multiple shoot cultures of Rauwolfia serpentina. Growth and alkaloid prodution. Journal Nat. Prod., 50: 872-875.

Thomas K. M. (1971). Jojoba oil wax esters and derived fatty acids and alcohols: gas chromatographic analysis. Journal of the American oil chemists' Society, 48 (6): 250264.

Wang Y.C. and Janick J. (1986). Somatic embryogenesis in jojoba. Journal Amer. Soc.
Hort. Sci. 111:281-287.

Wennuan L., David F.H. and Glenn B. (1995). Auxin-regulated changes of fatty acid content and composition in soybean zygotic embryo cotyledons. Plant Sci 106:31-42.

Zouari S., Najjaa H., Neffati M. and Ammar E. (2012). A new essential oil chemotype of Allium roseum analyzed by an apolar column. International Journal of Food Properties. 15: (2) 385-397.

$$
\begin{aligned}
& \text { تحليل زيت الجوجويا المستخلص من الكالهس الناتج من مزارع الانسجة النباتية، والزيت المستخرج }
\end{aligned}
$$

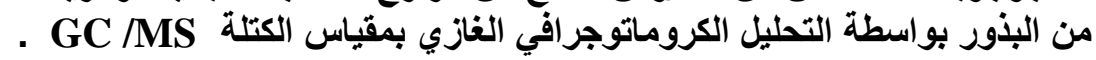

$$
\begin{aligned}
& \text { السعدى لحمل بدوى - *أسامة محم الثيحى - عفاف محمود حبيب - دعاء عادل أحمد } \\
& \text { قسم الزينة ـ * قسم النبات الزر اعى (فرع فسيولوجى نبات) كلية الزر اعة - جامعة القاهرة - الجيزة }
\end{aligned}
$$

\section{ملخص من من}

تم تحليل زيت الجوجوبا المستخلص من الكالوس الناتج من مزارع الانسجة النباتية باستخدام تقنية المدمجة بين التحليل

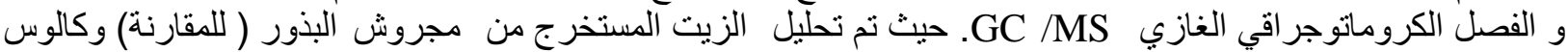

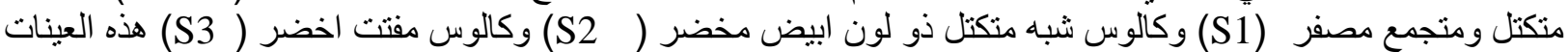

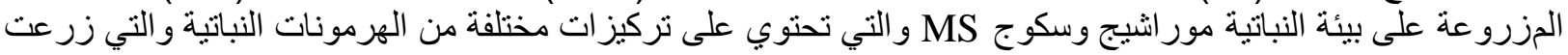

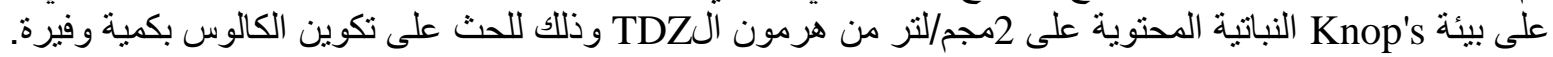

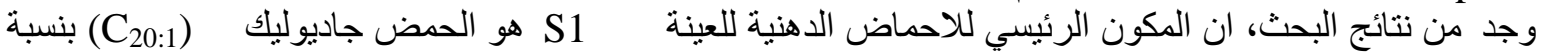

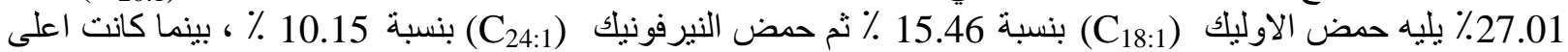

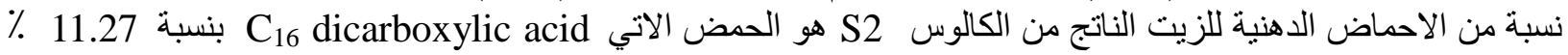

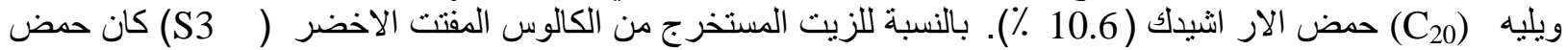

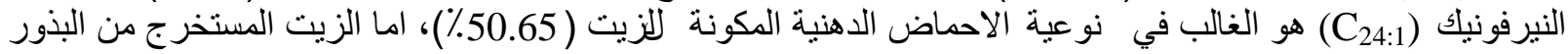

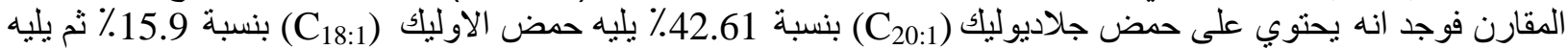

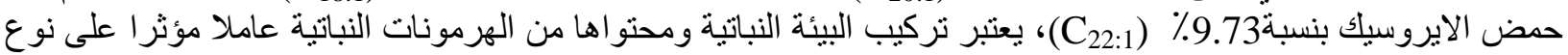
وكمبة الاحماض الإيرونة الدنية المكونة للزيت. 